\title{
Keynote: Data Archeology: A Theory Informed Approach to Analyz- ing Data Traces of Social Interaction in Large Scale Learning Envi- ronments
}

\author{
Alyssa Friend Wise \\ Faculty of Education \\ Simon Fraser University \\ 250-13450 102 Avenue \\ Surrey BC, Canada, V3T 0A3 \\ alyssa_wisedsfu.ca
}

\begin{abstract}
Data archeology is a theoreticallyinformed approach to make sense of the digital artifacts left behind by a prior learning "civilization." Critical elements include use of theoretical learning models to construct analytic metrics, attention to temporality as a means to reconstruct individual and collective trajectories, and consideration of the pedagogical and technological structures framing activity. Examples of the approach using discussion forum trace data will be presented.
\end{abstract}

\section{Overview}

Data traces that learners leave in online systems offer the possibility to study learning activity, predict outcomes, and designed targeted interventions for support (Siemens \& Long, 2011). However, such analysis often focus on rudimentary learning processes (series of related actions engaged in as part of learning activities) without attention to the larger learning practices they make up (repertoires of processes organized around particular foci that have meaning recognized within a particular context and social group) [Arastoopour et al., 2014]. This is an important concern for all learning analytics, but particularly problematic when the desired target of analytic claims is social interactions.

Lockyer, Heathcote \& Dawson (2013) conceptualize this issue through the relationship between learning analytics and learning design. That is, creation and interpretation of valid analytic measures needs to be grounded in the "the pedagogical and technical context in which the data [was] generated" (p. 1440). The practical implications of such are that the same analytic measures and patterns in these measures may be more or less useful, valid, and valued depending on the pedagogical goals of the activity at a particular point in time. For example, a discussion forum may be used in an online course course as a place for Q \&A with experts (or relatively expert-peers) or for common interest groups to work through different ways the course material might apply to a particular situation or challenge. A social network analysis of discussion replies that produces a wheel-and-spoke structure may be appropriate (and desired) for the former situation, but problematic in the latter (Brooks, Greer \& Gutwin, 2014).

To address these issues I describe the notion of data archeology (Wise, 2013) as theoreticallyinformed efforts to make sense of the digital artifacts left behind by a prior "civilization." Critical aspects of taking a data archeology perspective include: (a) the use of theoretical models of learning to frame the construction and interpretation of analytic metrics; (b) attention to temporality (of data and analytic methods) as a means to reconstruct individual and collective trajectories of engagement and interaction; and (c) consideration of the pedagogical and technological structures framing the activity that occurred. Such an approach supports the development of rich indicators that instructors and learners can recognize as meaningful reflections of their particular practices of teaching and learning.

Examples of a data archeology approach to discussion forum traces will be presented grounding in the work of the E-Listening project (Wise et al., 2012; 2013; 2014a; 2014b), a research effort connecting the comments learners make in online discussions with actions in attending to the posts of others (invisible to other learners, but visible in the clickstream record). The conceptual categories of online listening 
depth, breadth, integration and recursiveness will be introduced and their suitability for different kinds of technological and pedagogical discussion contexts discussed grounded in the framework of the following questions:

- What is the purpose of the educational activity taking place in the discussion forum?

- How does the design of the activity articulate with (support, inhibit) this purpose?

- What are expected (desired and undesirable) patterns of activity?

- How can these best be represented / proxied by the data available?

\section{References}

Arastoopour, G. et al. 2014. Analytics for Learning and Becoming in Practice. Proceedings of the International Conference of the Learning Sciences, 2014, 1680-1683.

Brooks, C., Greer, J. \& Gutwin, C. 2014. The DataAssisted Approach to Building Intelligent Technology Enhanced Learning Environments. In J. A. Larusson \& B. White (Eds.) Learning Analytics: From Research To Practice (pp. 123-156). New York: Springer.

Lockyer, L., Heathcote, E., \& Dawson, S. 2013. Informing Pedagogical Action: Aligning Learning Analytics with Learning Design. American Behavioral Scientist, 57(10): 1439-1459.

Siemens, G., \& Long, P. 2011. Penetrating the Fog: Analytics in Learning And Education. Educause Review, 46(5): 30-32.

Wise, A. F. 2013. Moving Beyond (Mere) Narrative. (Invited Talk), In Cyberinfrastructure for DesignBased Research Workshop, Madison, WI.

Wise, A. F., Hausknecht, S. N. \& Zhao, Y. 2014a. Attending to Others' Posts in Asynchronous Discussions: Learners' Online "Listening" and its Relationship to Speaking. International Journal of Computer-Supported Collaborative Learning, 9(2): 185-209.

Wise, A. F., Perera, N., Hsiao, Y., Speer, J. \& Marbouti, F. 2012. Microanalytic Case Studies of Individual Participation Patterns in an Asynchronous Online Discussion in an Undergraduate Blended Course. Internet and Higher Education, 15(2): 108-117.

Wise, A. F., Speer, J., Marbouti, F. \& Hsiao, Y. 2013. Broadening the Notion Of Participation in Online Discussions: Examining Patterns in Learners'
Online Listening Behaviors. Instructional Science. 41(2): 323-343.

Wise, A. F., Zhao, Y. \& Hausknecht, S. N. 2014b. Learning Analytics for Online Discussions: Embedded and Extracted Approaches. Journal of Learning Analytics, 1(2) : 48-71. 